\title{
UAVS SUPPORT TO NAVAL OPERATIONS
}

\author{
Valerian NOVAC, Eugen RUSU \\ "Dunărea de Jos" University, Galați, Romania \\ eugen.rusu@ugal.ro
}

\begin{abstract}
The paper proposes an analysis of Unmanned Aerial Vehicles (UAVS) features that enable them to support naval operations in general, but the focus drawn to the Black Sea basin peculiarities in particular. In the introductory part, the authors succinctly present the Black Sea basin's physical and strategic characteristics. Then, follows a description of UAVs features and potential missions conducted by these types of robots. In the next section, the article presents the uninhabited aerial vehicle classification and system components. The last chapter analyses the efficiencies and vulnerabilities of these vehicles. The closing section gives some short conclusions regarding the suitability of using such assets to support naval operations and a few further research directions.
\end{abstract}

\section{Keywords: UAVs, naval operations, Black Sea, robots}

\section{Introduction}

The real technological advance and miniaturization of essential components fuelled uninhabited vehicles in general and UAVs in the unique [1].

The UAVs can perform 4Ds missions: Dangerous - high risk of personnel death or injury; Dirty - acting in an infected environment with dangerous substances like Chemical, Biological, Radiological, or Nuclear (CBRN) agents; Demanding require a consistent effort from the crew side and Different - not appropriate for human-crewed vehicles [2].

These vehicles perform a plethora of tasks both in civilian and military domains. Some of these robots' civilian assignments are photogrammetry, wildlife monitoring, environment protection, crowd monitoring, cargo and passenger shipment in an unsafe environment, nearshore remote sensing, scientific exploration, or traffic monitoring [3 - 7]. Regarding military applications, they can complete: Intelligence
Surveillance and Reconnaissance (ISR), Mine Warfare (MiW), oceanographic tasks, act as communication platforms, Information Operations (IO), strike actions, surface and aerial warfare, electronic warfare, Battle Damage Assessment (BDA), support infiltration and extraction of troops, maritime security, deliver payloads, Search and Rescue (SAR), Special Operation Forces (SOF) support and so forth $[1,4,8,9]$.

The Black Sea basin is almost landlocked with a shallow region in the NW part [1113] favorable of employment of Unmanned Ground Vehicles (UGVs) [14] and Unmanned Underwater Vehicles (UUVs) [15]. From a strategic perspective, the previously mentioned sea basin has a complicated picture with six riparian states belonging or under the influence of two military powers, namely NATO and the Russian Federation [12]. Recent discoveries of oil and gas resources under the seabed raised the area's economic interest, and the 
naval operations will proportionally increase [16].

Though the exchange of waters is low, and the Black Sea is sensitive to any pollution; still, significant values of pollution are registered [13, 17, 18].

All the above activities claim UAVs' employment either for military purposes or for traffic or environment monitoring.

\section{UAVs structure characterization}

UAVs are the most used and developed uninhabited vehicles, so there are many approaches regarding their classification and description depending on the organization's affiliation or interest. This paper proposes an approach that serves the purpose of UAVs suitable to enable naval operations.

As specified in the previous section, the uncrewed vehicles are suitable for tasks and environments where the human crew cannot operate due to temperature, hazardous substances (CBRN), gravitation due to high altitude or duration $[2,6,19,20]$.

In the naval field, to operate such vehicles from the deck flight of a moving ship is not a simple task, especially during high seas or significant wind. Big waves also occur in the Black Sea basin during storms, mainly in the winter months [21 - 23].

\subsection{UAVs classification}

The article analyzes the UAVs type from many aspects like size, missions conducted, endurance, and autonomy level.

Table 1 UAVs types [3, 6, 19, 24]

\begin{tabular}{|c|c|c|c|}
\hline Type & Size & Flight Altitude & Endurance \\
\hline $\begin{array}{c}\text { MAV / NAV } \\
\text { (Micro or Nano Air } \\
\text { Vehicle) }\end{array}$ & $\begin{array}{c}\text { transported in } \\
\text { soldiers backpack }\end{array}$ & $<330 \mathrm{~m}$ & $<1$ hour \\
\hline $\begin{array}{c}\text { VTOL } \\
\text { (Vertical Take-Off \& } \\
\text { Landing) }\end{array}$ & various & $\begin{array}{c}\text { various but } \\
\text { predominantly low }\end{array}$ & size dependent \\
\hline $\begin{array}{c}\text { LASE } \\
\text { (Low Altitude, Short- } \\
\text { Endurance) }\end{array}$ & $\begin{array}{c}\text { weight }<5 \mathrm{~kg}, \\
\text { wingspan }<3 \mathrm{~m}\end{array}$ & $\leq 1500 \mathrm{~m}$ & $>4 \mathrm{~h}$ \\
\hline $\begin{array}{c}\text { LALE } \\
\text { (Low Altitude, Long- } \\
\text { Endurance) }\end{array}$ & $\begin{array}{c}\text { weight }<20 \mathrm{~kg}, \\
\text { wingspan }<4 \mathrm{~m}\end{array}$ & $<3000 \mathrm{~m}$ & $\sim 24-\mathrm{hour}$ \\
\hline $\begin{array}{c}\text { MALE } \\
\text { (Medium Altitude, } \\
\text { Long Endurance) }\end{array}$ & various \\
\hline $\begin{array}{c}\text { HALE } \\
\text { (High Altitude, Long } \\
\text { Endurance) }\end{array}$ & $\begin{array}{c}<\text { payle to bear a } \\
\text { paylof } 750 \mathrm{~kg}\end{array}$ & $>20000 \mathrm{~m}$ & $>17000 \mathrm{~km}$ \\
\hline
\end{tabular}

For naval applications, VTOL aircraft seem to be more suitable, taking into account the retrieval phase along with the ones launched with a catapult [6].

\subsection{UAVs architecture}

UAVs are mainly consisting of 5 major systems, namely planning and decision, sensing and perception, networking and collaboration, monitoring and diagnosis and human - system interface [1].
Planning and Decision - develop an arrangement of actions meant to achieve the mission objective. Sensing and Perception offers external awareness while the internal one comes from the Monitoring and Diagnosis.

Sensing and Perception - grabs data from sensors, integrates them, and depicts them to create a solid tactical picture for planning and decision systems. 


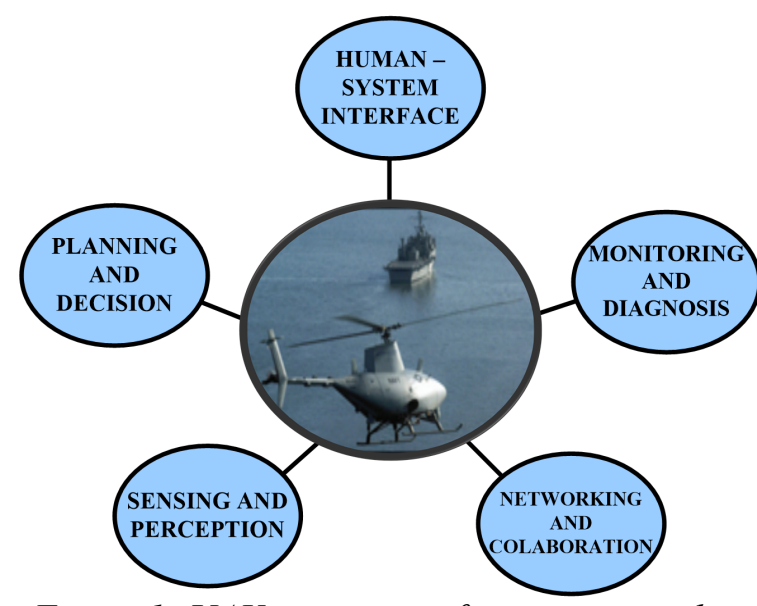

Figure 1: UAV systems configuration - author contribution after [1, 2]
Monitoring and Diagnosis - responsible for detecting faults and isolating them or reconfiguring the system when redundant capabilities are available.

Networking and Collaboration - administer data links, frequencies, and information content to change information and work paired with other human-crewed or uncrewed vehicles.

Human-System Interface - responsible for introducing data from a human operator, monitor sensor data, and direct the use of weapons or other payload components [1].

2.3. Levels of autonomy

UAVs have four levels of autonomy presented in the table below.

Table 2 UAVs levels of autonomy [1]

\begin{tabular}{|l|l|l|}
\hline \multicolumn{1}{|c|}{ Level } & \multicolumn{1}{|c|}{ Operator } & \multicolumn{1}{c|}{ System } \\
\hline I (manual operation) & $\begin{array}{l}\text { - supervise and controls all } \\
\text { mission functions }\end{array}$ & - autonomous flight \\
\hline $\begin{array}{l}\text { II (management by } \\
\text { consent) }\end{array}$ & - take key points decisions & $\begin{array}{l}\text { - recommend actions to } \\
\text { operator; } \\
- \text { ask operator for essential } \\
\text { decisions. }\end{array}$ \\
\hline $\begin{array}{l}\text { III (management by } \\
\text { exception) }\end{array}$ & $\begin{array}{l}\text { - revoke or modify mission } \\
\text { parameters; } \\
\text { - decide in case of ox } \\
\text { exception; }\end{array}$ & $\begin{array}{l}\text { excute missions } \\
\text { automatically; } \\
\text { inform the operator } \\
\text { regarding the mission } \\
\text { progress and exceptions; }\end{array}$ \\
\hline $\begin{array}{l}\text { IV (completely } \\
\text { autonomous) }\end{array}$ & $\begin{array}{l}\text { - warned regarding mission } \\
\text { progress }\end{array}$ & $\begin{array}{l}\text { conduct mission } \\
\text { automatically. }\end{array}$ \\
\hline
\end{tabular}

The analysis aims to cover all essential features of these types of systems while the spotlight is on their ability to support naval operations.

\section{Strengths, Weaknesses, Opportunities, And Threat analysis}

The analysis aims to cover all essential features of these types of systems while the spotlight is on their ability to support naval operations.

\subsection{Strengths}

Pairing with other $U x V s-\mathrm{UAV}$ s can be used in pair with other uninhabited platforms like UGVs, UUVs, or USVs (Unmanned Surface Vehicles) or with uncrewed counterparts enhancing in this way the communication for partner vehicle, or acting as a relay between uncrewed vehicles and their human crewed parents [1, 19, 25].

For littoral operations is very useful to have a UAV looking "over the hill" and one UGV searching inside building, holes, ducts, or other enclosed spaces [14].

As the Black Sea is a fundamental water turbidity level with a negative impact on underwater communications, a UAV can significantly improve an UUV's ability to communicate even immersed when raising above water level a small buoy antenna [15]. 
Conduct dirty operations - vehicles without human crew onboard are more suitable to operate within CBRN infested areas as they can be secured, and harmful agents are not allowed inside, and only external decontamination being more facile. A CBRN contaminated vehicle retrieved on a ship's board requires carefully handling [1, $2,19]$.

Reduction of the death toll is the main reason for using uncrewed vehicles, to prevent human lives from death or injury $[2,9]$.

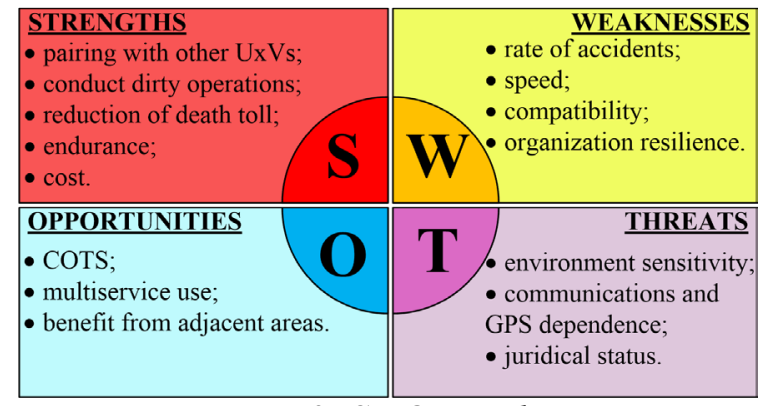

Figure 2: SWOT analysis

Endurance - compared with a human crewed vehicle, a UAV can operate for tens of hours in hostile environments, and ground crew shifted during the vehicle flight. The endurance of these vehicles is mostly limited by the fuel tank's capacity or exhausting battery period. Nowadays, for liquid fuel propelled vehicles, as there are capabilities for aerial refueling (MQ-25 'Stingray') available, these vehicles' endurance increased $[1-4,6,24]$.

Cost - as the vehicle's cost is slightly corresponding with size and weight, it is easy to conclude that compared with human-crewed vehicles is lower. Uncrewed vehicles do not require a crew cabin or a series of safety gear like a catapult. Moreover, the program cost is lower as the ground crew training is shorter and performed by simulation $[1,9,30,31]$.

\subsection{Weaknesses}

Rate of accidents - the accident rates of this kind of vehicles is more extensive than for human-operated ones as they can lose the radio link with a control station and can fly uncontrolled or even fall being a hazard for humans or properties on the ground or even other aircrafts flying in the same airspace. It is necessary to provide these aircraft with a collision-avoidance system and develop a learning and adaptation module to mitigate the risks of accidents.

Onboard of a ship is even more difficult to retrieve a UAV, which lost the radio link even if the aircraft is preset to land on a specific position, but the mother ship is moving [1, 19, 24, 31].

Speed. Although developed applications could fly at speeds comparable with their crewed counterparts in the last period, most of them fly at lower speeds [1].

Compatibility - to use the same assets for multiple services or even paired with a ship, the communications systems, and control equipment must be compatible. Once solved by compatibility, the UAV program's cost will decrease as the same assets used for multiple services or missions [11].

Organization resilience - there are many leaders and organizations old-style who prefer human-crewed vehicles to crewless ones or biased regarding the missions conducted by UAVs thinking about UAVs just as Intelligence Surveillance and Reconnaissance equipment [9].

\subsection{Opportunities}

COTS - Commercial On The Shelf components availability fuelled the UAVs' development in the military area. This large availability, especially regarding communications equipment, is because of UAVs used in many fields, from civilian applications to military ones [32].

Multiservice use - to avoid competition between programs or between services, the vehicles can be shared between services or use the products (intelligence gathered) in common. To make this possible, systems need to be compatible to change information or be controlled by more users upon specific requirements - distributed control [1]. 
Benefit from adjacent areas - military UAV programs can use the research results obtained in adjacent domains like border surveillance or scientific research $[4,6]$.

\subsection{Threats}

Environment sensitivity - it is known that small aircraft encounter more difficulties when passing through areas with turbulent air layers. For such vehicles operated from ships, the retrieval phase is also tricky when the ship encounters high seas, and the ship moves due to the waves.

Another issue regarding UAVs is related to sensors. Electro-Optical (EO) and infrared (IR) sensors cannot penetrate clouds as radar can do, but technology is challenging to realize a miniature radar. To 'see' beyond the clouds and achieve an excellent Positive Identification of target, the designers it is desirable to use a combination of $\mathrm{EO} / \mathrm{IR}$ with a miniaturized radar; of course, this will increase the arrangement's overall cost $[1,31]$.

Communication and GPS dependence - as the UAVs are radio-controlled assets, allimportant control, and data exchange activities use radio communication, which is satellite dependent, they are vulnerable to jamming or even kinetic attacks against satellites. The same issue happens with GPS dependence for positioning and control. The constellation of satellites from the spatial segment of GPS naked to attacks from jamming to kinetic ones [2].

Juridical status - these vehicles' legal status is still not exact, and not decided if the UAVs should have the same status as human-crewed aircraft. The border between force protection of the mother ship, which is allowed, and intelligence gathering is very porous.

The operation of these vehicles in the civilian airspace is also not regulated by some authorities restricting these vehicles' operations in certain areas. Not, at last, the public perception and implicit political leaders are not all the time favorable to the employment of these vehicles [3].

\section{Conclusions}

Due to their advantages compared with human-crewed aircraft, UAVs are real force multipliers being cheaper to operate and conduct 4Ds operations. though they have many strong points, issues like the significant dependency of GPS and communications satellites or legal aspects of employment remain to be solved.

External military organization issues remain to address and biased commanders considering UAVs just ISR assets or preferring just human-crewed vehicles delay implementing these enablers.

From the technical perspective, issues like sensing and perception, human-machine interface, collision avoidance, learning, and adaptation remain under the researcher's attention.

\section{Acknowledgement}

This work was carried out in the framework of the research project DREAM (Dynamics of the REsources and technological Advance in harvesting Marine renewable energy), supported by the Romanian Executive Agency for Higher Education, Research, Development and Innovation Funding - UEFISCDI, grant number PN-III-P4-ID-PCE-2020-0008.

\section{References List}

[1] National Research Council, Autonomous Vehicles in Support of Naval Operations. Washington D C, The National Academies Press, ISBN 978-0-309-38616-6, 256 p., 2005.

[2] B. Alkire, J. G. Kallimani, P. A. Wilson and L. R. Moore, Applications for navy unmanned aircraft systems, National Defense Research Institute, ISBN 978-0-83304965-0, 96 p., RAND Corporation, Santa Monica, USA, 2010.

[3] L. Fiori, A. Doshi, E. Martinez, M. Orams and B. Bollard-Breen, The Use of Unmanned Aerial Systems in Marine Mammal Research, Remote Sensing, Vol. 9, Is. 543, pp. 1 13, 2017. 
[4] G. C. Rosa, M. M. Marques and V. Lobo, Unmanned aerial vehicles in the navy: its benefits, "Mircea cel Batran" Naval Academy Scientific Bulletin, Vol. XIX, Iss. 1, pp. $39-43,2016$.

[5] E. W. J. Bergsma, R. Almar, L. P. Melo de Almeida and M. Sall, On the operational use of UAVs for video-derived bathymetry, Coastal Engineering, Vol. 152, pp. $1-8$, 103527, 2019.

[6] A. C. Watts, V. G. Ambrosia and E. A. Hinkley, Unmanned Aircraft Systems in remote sensing and scientific research: classification and considerations of use, Remote Sensing, Vol. 4, pp. 1671-1692, 2012.

[7] A. Zanutta, A. Lambertini and L. Vittuari, UAV Photogrammetry and Ground Surveys as a Mapping Tool for Quickly Monitoring Shoreline and Beach Changes, Journal of Marine Sciences and Engineering, Vol. 8, Iss. 52, pp. 1-16, 2020.

[8] R. S. Carapau, A. V. Rodrigues, M. M. Marques and V. Lobo, Unmanned aerial systems in military environments: the benefits of interoperability, "Mircea cel Batran" Naval Academy Scientific Bulletin, Vol. XX, Iss. 1, pp. 43 - 47, 2017.

[9] G. Smith, Organization and Innovation, Naval War College Review, Vol. 70, No. 3, Art. 6, pp. 78-100, 2017.

[10] G. Wilkinson, Flying into the future, Navy News, Is. 787, pp. 19, 2020.

[11] V. Novac, E. Rusu and G. Stăvărache, Black Sea naval accidents - intervention management, Mechanical Testing and Diagnosis, IX, Volume 2, pp. 11-14, 2019.

[12] V. Novac and E. Rusu, Black Sea littoral military operations - environment impact, Scientific Bulletin of Naval Academy, Vol. XXI, pp. 607-616, 2018.

[13] V. Novac and E. Rusu, Black Sea oil spills - preventive and remedial actions, 19th International Multidisciplinary Scientific Conference - SGEM 2019, Conference Proceedings, Vol. 19, Iss. 3.1, pp. 683-690, 2019.

[14] V. Novac, E. Rusu and O. Cosma, UGVs support to naval operations, International Conference KNOWLEDGE-BASED ORGANIZATION, Conference Proceedings, Vol. XXVI, No. 3, pp. 152 - 157, 2020.

[15] V. Novac, E. Rusu and I. C. Scurtu, UUVs support to naval operations, Scientific Bulletin of Naval Academy, Vol. XXIII, pp. 47-54, 2020.

[16] V. Novac, E. Rusu and I. C. Scurtu, Opportunities and risks related to offshore activities in the western Black Sea, Journal of Environmental Protection and Ecology, Vol. 20, No 4, pp. 1698-1707, 2019.

[17] V. Novac and E. Rusu, Air emission from ships - western Black Sea case study, 19th International Multidisciplinary Scientific Conference - SGEM 2019, Conference Proceedings, vol. 19, issue 4.1, pp 813-819, 2019.

[18] V. Novac, L. Moraru, C. Gasparotti, and E. Rusu, Black sea marine litter pollution related to naval operations, E3S Web of Conferences, TE RE RD 2020 International Conference Proceedings, Vol. 180, 04018, pp. 1- 7, 2020.

[19] G. Răducanu and I. Cîrciu, Unmanned Aerial Vehicle future development trends, Review of the Air Force Academy, No. 3, 35, pp. 105-110, 2017.

[20] A. V. Rodrigues, R. S. Carapau, M. M. Marques and V. Lobo, Unmanned Aerial Vehicles: system architecture and protocols, "Mircea cel Batran" Naval Academy Scientific Bulletin, Vol. XX, Iss. 1, pp. 113 - 116, 2017.

[21] E. Rusu and D. Butunoiu, Prediction of the extreme storms in the Black Sea with numerical wave models, Proceedings of $16^{\text {th }}$ International Congress of the International Maritime Association of the Mediterranean, Vol. 2015, pp.845 -851, Taylor \& Francis Group, London, ISBN 978-1-138-02887-6, 2015. 
[22] E. Rusu, F. Onea and R. Toderascu, Dynamics of the environmental matrix in the Black Sea as reflected by recent measurements and simulations with numerical models, Chapter 3 in The Black Sea: Dynamics, Ecology and Conservation, pp. 1 - 34, ISBN: 978-1-61122-855-7, Nova Science Publishers, Inc. , 2011.

[23] L. Rusu, D. Butunoiu and E. Rusu, Analysis of the Extreme Storm Events in the Black Sea Considering the Results of a Ten-year Wave Hindcast, Journal of Environmental Protection and Ecology, Vol. 15, No 2, pp. 445-454, 2014.

[24] J. D. Stevenson, S. O'Young and L. Rolland, Estimated levels of safety for small unmanned aerial vehicles and risk mitigation strategies, Journal of Unmanned Vehicle Systems, Vol. 3, pp. 205-221, 2015.

[25] S. Pop, A. Luchian, R. G. Zmădu and E. Olea, The evolution of Unmanned Aerial Vehicles, Review of the Air Force Academy, No.3 (35), pp. 125 - 132, 2017.

[26] E. Stanev, Understanding Black Sea Oceanography, An Overview of Recent Numerical Modeling, Oceanography, Vol.18, No.2, pp. 56-75, 2005.

[27] A. Kara, A. J. Wallcraft and H. E. Hurlburt, Sea Surface Temperature Sensitivity to Water Turbidity from Simulations of the Turbid Black Sea Using HYCOM, Journal of physical oceanography, Volume 35, pp. 33-54, 2005.

[28] A. Kara, A. J. Wallcraft and H. E. Hurlburt, A New Solar Radiation Penetration Scheme for Use in Ocean Mixed Layer Studies: An Application to the Black Sea Using a FineResolution Hybrid Coordinate Ocean Model (HYCOM), Journal of physical oceanography, Volume 35, pp. 13-32, 2005.

[29] J. Bronk, The US Navy's MQ-25 Unmanned Tanker Will Shape the Future of Airpower, RUSI Newsbrief, Vol. 38, No. 3, pp. 1-3, 2018.

[30] J. G. Dalton, Future Navies-Present Issues, Naval War College Review, Vol. 59, pp. 15-39, 2006.

[31] A. la Cour-Harbo, Quantifying Risk of Ground Impact Fatalities for Small Unmanned Aircraft, Journal of Intelligent \& Robotic Systems, Vol. 93, pp. 367-384, 2019.

[32] R. Louali, A. Elouardi, S. Bouaziz and M. S. Djouadi, Experimental Approach for Evaluating an UAV COTS-Based Embedded Sensors System, Journal of Intelligent \& Robotic Systems, Vol. 83, pp. 289-313, 2016. 